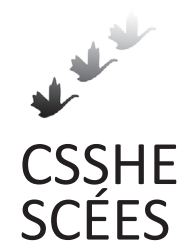

Canadian Journal of Higher Education Revue canadienne d'enseignement supérieur

Volume 45, No. 4, 2015, pages 343 - 360

\title{
Student Affairs in Canada in 2013: Perceptions, Trends, and an Outlook Toward the Future
}

Jennifer Browne, David Speed, \& Lilly Walker Memorial University

\begin{abstract}
Chief Student Affairs Officers (CSAOs) are senior-level student affairs personnel. In 2011, 33 CSAOs responded to a national survey and provided a professional perspective on field development, student services, as well as predicted five-year trends for student affairs. In 2013, 17 CSAOs responded to the same survey and provided further information on these topics. Results indicated that attitudes towards diversity and technology remained stable between 2011 and 2013. We established that CSAOs have less positive attitudes towards research, evaluation, and assessment than they do towards communication and leadership. Here, we discuss at length the implications of these finding, as well as the potential for research into student affairs. In addition, we examine the continued professionalization of the CSAO field and note that research into CSAOs should be proactive instead of reactive.
\end{abstract}

\section{Résumé}

Les directeurs des affaires étudiantes sont des membres du personnel des affaires étudiantes aux niveaux supérieurs. En 2011, 33 de ces directeurs ont répondu à un sondage national et fourni une perspective professionnelle sur la mise en valeur de leur domaine, sur les services aux étudiants, ainsi que sur leurs prédictions des tendances des cinq prochaines années pour les affaires étudiantes. En 2013, 17 directeurs ont répondu au même sondage et ont fourni plus de données sur ces mêmes sujets. Les résultats indiquaient que les attitudes envers la diversité et la technologie étaient demeurées stables entre 2011 et 2013. Nous avons pu établir que les directeurs présentent des attitudes moins positives envers la recherche, l'évaluation et les épreuves, qu'envers la communication et le leadership. Nous nous attardons ici sur les implications de ces découvertes, de même que sur leur potentiel pour la recherche au sujet 
des affaires étudiantes. Nous discutons aussi de la professionnalisation du domaine des directeurs des affaires étudiantes et notons que la recherche au sujet des directeurs doit être proactive plutôt que réactive.

Professionalism at postsecondary institutions represents a substantial field of interest for researchers. Often, discussions of this subject are limited to instructors being assessed on their research or teaching abilities. While this is inarguably an important area of professionalism, it is not a complete picture of the complex workings of a postsecondary institution (Pittman, 2012). Numerous support staff fulfill critical roles within institutions, not as instructors but as facilitators between the student body and various facets of the institutions (Lawrence, 2007). One of the most critical of these facilitating roles is that of student affairs professional (SAP).

"Student affairs" is a somewhat vague term that literally refers to all formalized elements of student/institution interaction. Because this covers a wide range of many possible activities, the term is not particularly informative. Conceptually, SAPs are responsible for ensuring that the evolving needs of students are met (Ellis, 2010; Hardy-Cox \& Strange, 2010; McGraw, 2011). This task is challenging, as student affairs departments are often reacting to students' needs after those needs begin to exist. Because needs can exist in a wide array, identifying issues before they become significant presents a viable avenue of academic research.

Generally, the mantra of postsecondary institutions is simple: different students need different things to succeed, and postsecondary institutions should be there to help (Kuh, Kinzie, Schuh, \& Whitt, 2011). The professional decisions that SAPs make can influence the health of students (Shuler, 2000) and can also affect the graduation rates of students experiencing difficulties (Carini, Kuh, \& Klein, 2006). Acclimating to postsecondary institutions can be stressful (Duenwald, 2004; Jou \& Fukada, 2002), and in recent years there have been increased concerns about violence (Sandeen \& Barr, 2006; Walker, Stewart, \& Eerkes, 2009). A nurturing institution not only is helpful to students-it also is good business practice. Because of this, SAPs are often involved in actively retaining students (Ellis, 2010). Retention efforts come in several varieties but are popularly known as "student success" programs. Hence, postsecondary institutions are not faceless entities to students but a vast network of academic and social support for them.

While SAPs play an important role within higher education, research into the field faces several roadblocks. Academic research on SAPs is occasionally limited because the roles of SAPs are diverse. SAPs have many responsibilities, in numerous fields: for example, postsecondary education, evaluation, organizational psychology, etc. Additionally, academic publications addressing SAPs are oriented towards professional development, not academic research. Of the existing academic research, much is reactive rather than proactive. The lack of proactive academic research into student affairs means that often, issues must exist before being dealt with.

While professional SAPs organizations exist within North America, they often prioritize the professional development of the field. Again, this is due in part to the wide variety of roles played by SAPs. While there are several wonderful examples of research addressing success stories or practices in specific institutions (e.g., Kuh, 2013), these often address how a problem was solved. SAPs could greatly benefit from potential issues being identified prior to becoming substantive issues. For SAPs to "get ahead of the curve," they need access to proactive academic research addressing future trends. 


\section{The Current Study}

Some researchers have already pioneered a degree of proactive research into SAPs (Browne, 2007; Browne \& Shea, 2002; Walker, 1994a, 1994b, 1996, 1997, 1998); however, this research is somewhat fragmented. The current study sought to address what SAPs in leadership positions at universities and colleges thought were the major issues facing their institutions, staff, and students in the present time, and what issues would be faced over the next five years. Because there is no standard title for senior-level SAPs, the researchers used the term "chief student affairs officer" (CSAO) to indicate the most senior level of a student affairs administration. The researchers collected longitudinal data in 2011 and again in 2013 to assess the changes the field had experienced in that time frame. They were particularly interested in evolving views of technology and diversity, perceptions of economic difficulties, attitudes toward research, and whether degree programs in student affairs would become more favourably perceived across time.

The researchers collecting data in 2011 were able to gather a wealth of information on the demographics, perspectives, and concerns of CSAOs. When data were collected again in 2013, the researchers were able to compare the two populations approximately two years apart. The researchers formulated several hypotheses regarding the data:

1. Attitudes towards technology and diversity would not have changed between 2011 and 2013.

2. Economic concerns at the institutional level were the most frequently cited in 2011 and would be the most cited in 2013 as well.

3. Attitudes toward research, evaluation, and assessment would be significantly less positive than attitudes toward leadership and communication.

4. Student affairs degrees (as a method of professional development) would be more valued in 2013 than in 2011.

5. Physical and mental well-being issues (i.e., "health") would be identified as the most prevalent student issue over the next five years.

\section{Methods}

\section{Participants}

The researchers sought to use a sampling frame that would encompass as many CSAOs as possible. They initially used a list of institutions within Canada, generated by the Canadian Association of College and University Student Services (CACUSS), then reviewed various resources (e.g., Maclean's magazine) to augment the initial listing. After the list of Canadian postsecondary institutions was completed, the researchers gathered the CSAO's contact information from the respective institution's website. If the researchers were unable to find the information online, they contacted the institution to confirm the CSAO's identity and acquire his/her contact information. Participants were recruited at two time intervals, once in 2011 and again in 2013. In 2011, a total of 33/104 Canadian CSAOs provided information to researchers (28.5\% response rate). In 2013, a total of 17/90 Canadian CSAOs provided information to researchers (18.8\% response rate). The discrepancy between the number of institutions contacted (105 vs. 90) was due to various factors (e.g., administrative reshuffling or a reduction in student affairs services on specific campuses). French responses were received only in 2011. 


\section{Measures}

The metric used to collect all data on CSAOs was a modified version of a survey created by Rybalkina (2004). The metric consisted of 116 questions over four sections. The Rybalkina measure was originally designed to assess SAPs on topics relevant to their field. We added several sections to the original measure in order to access a wider range of information from respondents. The authors received permission from Rybalkina to modify her measure and use it in the current study. The following paragraphs briefly describe the modified measure.

Section I (Skills and Competencies) made up the bulk of the survey and consisted of several multiple-question subscales addressing a variety of topics. In each case, the question began with "How important is." The topics were: Leadership (e.g., "utilizing effective techniques to motivate staff"); Student Contact (e.g., "responding to students' crises"); Communication (e.g., "making oral presentations/public speaking"); Human Resources Management (e.g., "mediating conflict among staff"); Fiscal Management (e.g., "analyzing financial reports"); Personal Development (e.g., "attending professional development activities"); Research, Evaluation, and Assessment (e.g., "utilizing results of studies"); Legal Issues (e.g., "implementing due process concepts"); Technology (e.g., "using technology to find information"); and Diversity (e.g., "understanding needs of underrepresented students"). All items for all subscales were rated on a four-point scale to indicate importance ( 1 = This is essential, $2=$ This is important, $3=$ This is somewhat important, $4=$ This is not important).

Section II (Professional Development Methods) had respondents rate the effectiveness of approaches to professional development (e.g., Webinars, international exchange visits, books, professional journals, etc.). Section III had respondents provide information on what they thought would be the most important student, institutional, and professional issues for CSAOs during the next year and five-year period. Finally, Section IV recorded CSAOs' demographic information, including sex, experience, institution size, etc. Surveys took an estimated 20-25 minutes to complete, depending on how detailed the respondent made his/her replies. To encourage equally accessible data collection, the survey was translated into French, then backwards translated to ensure the reliability of the measure.

The researchers used a mixed-methods approach to data collection, utilizing quantitative assessments of Skills and Competencies, Professional Development, and Demographics, but collecting qualitative data for Future Trends (Section III). Qualitative data was collected for Section III because the researchers did not want to limit respondents' choices regarding what they expected the future to hold. They then quantified the respondents' trend predictions for the coming years, permitting a quantitative assessment of the respondents' qualitative choices. This was particularly useful because many of the responses were very brief and easily quantified.

\section{Procedure}

A similar procedure was followed in 2011 and 2013. To distribute a survey to a national sample, the researchers used an online mass-emailing system that was able to standardize how respondents received the measure. The mass-emailing system delivered a notice of upcoming research to all potential participants; three days later, the survey was distributed. In 2011, data collection occurred over a two-week period in February, while 
in 2013, data collection occurred over a two-week period in May. This change in timing was due to technical issues with the mass-emailing system. The researchers are unsure of the effect of delaying the period of research.

Potential respondents received an email inviting them to participate in research relevant to student affairs. Respondents received either an English or a French invitation, the language of choice being determined by where the postsecondary institution was located; institutions in Québec and New Brunswick received French invitations, while the remaining CSAOs received English ones. One respondent, upon receiving a French invitation, contacted the researchers (through a provided email address) and requested an English survey instead.

In the invitations, respondents were asked to click on a link to the survey distribution site. Once respondents selected the link, they were informed that their participation was functionally anonymous and wholly voluntary. The survey distribution system was able to reduce missing data issues by prompting respondents to reply to unanswered questions. Respondents were not compensated in any way for their participation, although they were informed that their responses would be helpful to the SAP field. Participants who did not respond within five days were emailed the invitation again, and were sent a final reminder email at the 10-day mark.

\section{Data Analysis}

Data collected on the survey distribution site were exported to Microsoft Excel and then to IBM SPSS 21. Quantitative data were not prepared or altered in any fashion. There were no concerns over non-valid outliers because the survey distribution site did not allow impermissible values. Qualitative data were assessed by a researcher and then placed into categories denoting the theme of the response. For responses that had more than one theme, the first theme mentioned was the only one used in the interpretation. If a response was ambiguous, it was omitted from the analyses.

\section{Results}

Demographic data were collected in both 2011 and 2013. As can be seen in Table 1, there are some notable demographic differences between 2011 and 2013, but there are also many similarities. Some notable differences between the 2011 and 2013 data are the years of CSAO experience reported. This sudden jump from 4.23 years to 10.04 years is likely the product of fewer people participating in 2013, making the average vulnerable to more extreme numbers. It is also noteworthy that while no school with a population under 5,000 responded in 2011, four such schools responded in 2013.

The demographic differences between 2011 and 2013 may contribute to statistical differences between the two years. Because the overall number of Canadian CSAOs was less than 100 in 2013 and only 104 in 2011, differences between samples are susceptible to outliers. However, it is important to remember that a general purpose of the current study is to provide baseline data from year to year for CSAOs. This may result in different samples (comprised of potentially different individuals) providing varying information. Nonetheless, repeated sampling from survey year to survey year will result in a more consistent and reliable baseline across time. So, while the exact sample from any year may have non-representative variability, there is still great value in reporting the existing data. 
Table 1 .

Demographics of CSAOs for 2011 and 2013

\begin{tabular}{|c|c|c|c|}
\hline & & \multicolumn{2}{|c|}{ Year } \\
\hline & & 2011 & 2013 \\
\hline \multirow[t]{2}{*}{ Sex } & Male & 15 & 5 \\
\hline & Female & 15 & 9 \\
\hline \multirow[t]{2}{*}{ Experience } & SAP Experience & 21.59 years & 20.93 years \\
\hline & CSAO Experience & 4.23 years & 10.04 years \\
\hline \multirow[t]{4}{*}{ Level of Education } & Bachelor's & 1 & O \\
\hline & Master's & 18 & 11 \\
\hline & Doctorate & 10 & 3 \\
\hline & Other & 1 & $\mathrm{O}$ \\
\hline \multirow[t]{2}{*}{ Degree Type } & Education-Related & $12(40 \%)$ & $11(65 \%)$ \\
\hline & Non-Education-Related & $18(60 \%)$ & $6(35 \%)$ \\
\hline \multirow[t]{5}{*}{ School Type } & Public University & 20 & 9 \\
\hline & Public College & 7 & 2 \\
\hline & Private University & 2 & o \\
\hline & Private College & 1 & $\mathrm{O}$ \\
\hline & Other & $\mathrm{O}$ & 3 \\
\hline \multirow{5}{*}{$\begin{array}{l}\text { School Size } \\
\text { (number of students) }\end{array}$} & $<1,500$ & $\mathrm{O}$ & 1 \\
\hline & $1,501-5000$ & o & 3 \\
\hline & $5,001-10,000$ & 10 & 4 \\
\hline & $10,001-20,000$ & 10 & 2 \\
\hline & $20,001+$ & 10 & 4 \\
\hline
\end{tabular}

CSAOs were asked in 2011 and again in 2013 to provide their opinions on what would be the biggest issues a year from then and five years from then. Table 2 presents the top three responses for each area of concern and year.

The researchers collected a variety of demographic data as well as data on attitudes towards a variety of CSAO responsibilities. The following tables provide the relevant breakdown of how attitudes towards a variety of topics varied as a function of various demographic indicators. It should be noted that demographic differences between 2011 and 2013 would suggest that comparisons between the two should not be made solely on the basis of means, as there may be an issue with representativeness in 2011. Table 3 indicates the means and standard deviations for leadership, student contact, communication, HR management, fiscal management, personal development, research/evaluation/ assessment, legal, technology, and diversity, by year.

Table 4 indicates the means and standard deviations for leadership, student contact, communication, HR management, fiscal management, personal development, research/ evaluation/assessment, legal, technology, and diversity, by the respondent's degree. Data were collected on specific degree type, but this information was collapsed for the purpose of analysis. Data were combined for years 2011 and 2013. 
Table 2.

The CSAO's Top Three Greatest Concerns About the Future

\begin{tabular}{|c|c|c|c|}
\hline \multicolumn{2}{|c|}{ Area of Concern } & \multicolumn{2}{|c|}{ Greatest Concerns by Year } \\
\hline & & 2011 & 2013 \\
\hline \multirow[t]{6}{*}{ Student } & 1 Year & Health & Health \\
\hline & & Student engagement & Student engagement \\
\hline & & Economic & Increased diversity \\
\hline & 5 Years & Increased diversity & Health \\
\hline & & Students' changing expectations & Economic \\
\hline & & Economic & Increased diversity \\
\hline \multirow[t]{6}{*}{ Staff } & 1 Year & Leave* & Service delivery \\
\hline & & Administrative changes & Economic \\
\hline & & Professional development & Burnout \\
\hline & 5 Years & Leave $^{*}$ & Recruitment \\
\hline & & Professional development & Economic \\
\hline & & Economic & Effective technology use \\
\hline \multirow[t]{6}{*}{ Institution } & 1 Year & Economic & Economic \\
\hline & & Administrative changes & Institution politics \\
\hline & & Growth/no space & Administrative changes \\
\hline & 5 Years & Economic & Economic \\
\hline & & Growth/no space & Institutional politics \\
\hline & & Enrolment & Enrolment \\
\hline \multirow[t]{3}{*}{ Decade } & & Students' changing expectations & Economic \\
\hline & & Economic & Health \\
\hline & & Demographic shifts & Demographic shifts \\
\hline
\end{tabular}

${ }^{*}$ Covers a wide variety of topics, including burnout, retirement, maternity leave, and turnover.

Table 3 .

Measures of Central Tendency by Year

\begin{tabular}{lcc}
\hline & 2011 & 2013 \\
\cline { 2 - 3 } & $\mathrm{M} / \mathrm{SD}$ & $\mathrm{M} / \mathrm{SD}$ \\
\hline Leadership & $1.39 / 0.53$ & $1.56 / 0.40$ \\
Student Contact & $1.68 / 0.61$ & $1.87 / 0.51$ \\
Communication & $1.56 / 0.51$ & $1.56 / 0.41$ \\
HR Management & $1.72 / 0.62$ & $1.81 / 0.50$ \\
Fiscal Management & $1.69 / 0.61$ & $1.77 / 0.56$ \\
Personal Development & $1.96 / 0.65$ & $2.10 / 0.51$ \\
Research/Evaluation/Assessment & $1.98 / 0.63$ & $2.09 / 0.52$ \\
Legal & $1.65 / 0.58$ & $1.56 / 0.44$ \\
Technology & $1.71 / 0.51$ & $1.81 / 0.50$ \\
Diversity & $1.57 / 0.61$ & $1.53 / 0.43$ \\
\hline
\end{tabular}


Table 4.

Measures of Central Tendency by Degree Type

\begin{tabular}{|c|c|c|c|c|c|c|}
\hline & $\begin{array}{c}\text { Business } \\
\mathrm{M} / \mathrm{SD}\end{array}$ & $\begin{array}{c}\text { Education } \\
\mathrm{M} / \mathrm{SD}\end{array}$ & $\begin{array}{c}\text { Humanities } \\
\mathrm{M} / \mathrm{SD}\end{array}$ & $\begin{array}{c}\text { Physical } \\
\text { Science } \\
\text { M/SD }\end{array}$ & $\begin{array}{c}\text { Social } \\
\text { Science } \\
\text { M/SD } \\
\end{array}$ & $\begin{array}{l}\text { Other } \\
\text { M/SD }\end{array}$ \\
\hline Leadership & $1.31 / 0.53$ & $1.54 / 0.45$ & $1.21 / 0.25$ & $1.25 /$. & $1.28 / 0.48$ & $1.47 / 0.73$ \\
\hline Student Contact & $1.57 / 0.62$ & $1.89 / 0.57$ & $1.29 / 0.20$ & $1.57 /$. & $1.67 / 0.30$ & $1.81 / 0.76$ \\
\hline Communication & $1.40 / 0.53$ & $1.62 / 0.42$ & $1.40 / 0.28$ & $1.40 /$. & 1.13/o.12 & $1.64 / 0.63$ \\
\hline HR Management & $1.57 / 0.57$ & $1.77 / 0.51$ & $1.38 / 0.43$ & $1.80 /$. & $1.70 / 0.44$ & $1.93 / 0.74$ \\
\hline Fiscal Management & $1.71 / 0.52$ & $1.82 / 0.58$ & $1.32 / 0.27$ & $1.71 /$. & $1.48 / 0.22$ & $1.83 / 0.79$ \\
\hline 1 Develop- & $1.94 / 0.48$ & $2.11 / 0.58$ & $1.54 / 0.37$ & $2.00 /$. & $2.00 / 0.58$ & $2.13 / 0.67$ \\
\hline $\begin{array}{l}\text { Research/ } \\
\text { Evaluation/ Assess- } \\
\text { ment }\end{array}$ & .59 & 2.04 & 1.6 & $2.13 /$. & / 0.43 & 0.63 \\
\hline Legal & $1.60 / 0.53$ & $1.62 / 0.48$ & $1.60 / 0.59$ & $1.80 /$. & $1.47 / 0.12$ & $1.76 / 0.69$ \\
\hline Technology & $1.42 / 0.52$ & $1.80 / 0.44$ & $1.50 / 0.35$ & $2.00 /$. & $1.67 / 0.29$ & $1.89 / 0.55$ \\
\hline Diversity & $1.50 / 0.73$ & $1.64 / 0.50$ & $1.13 / 0.25$ & $1.50 /$. & $1.56 / 0.67$ & $1.65 / 0.71$ \\
\hline
\end{tabular}

Table 5 indicates the means and standard deviations for leadership, student contact, communication, HR management, fiscal management, personal development, research/ evaluation/assessment, legal, technology, and diversity, by institution size. Data were combined for years 2011 and 2013. It is important to note that 2011 saw a bias towards large institutions (no one from institutions < 5,000 responded), while in 2013 about 30\% of respondents were from small institutions.

Table 5 .

Measures of Central Tendency by Institution Size

\begin{tabular}{|c|c|c|c|c|c|}
\hline & $<1,500$ & $\begin{array}{l}1,501- \\
5,000 \\
\end{array}$ & $\begin{array}{l}5,001- \\
10,000 \\
\end{array}$ & $\begin{array}{l}10,001- \\
20,000\end{array}$ & $20,001+$ \\
\hline & $\mathrm{M} / \mathrm{SD}$ & $\mathrm{M} / \mathrm{SD}$ & $\mathrm{M} / \mathrm{SD}$ & $\mathrm{M} / \mathrm{SD}$ & $\mathrm{M} / \mathrm{SD}$ \\
\hline Leadership & $1.27 / 0.41$ & $1.75 / 0.65$ & $1.32 / 0.32$ & $1.45 / 0.45$ & $1.45 / 0.60$ \\
\hline Student Contact & $1.40 / 0.43$ & $2.06 / 0.84$ & $1.73 / 0.43$ & $1.81 / 0.58$ & $1.73 / 0.63$ \\
\hline Communication & $1.40 / 0.40$ & $1.84 / 0.52$ & $1.45 / 0.32$ & $1.53 / 0.43$ & $1.53 / 0.56$ \\
\hline HR Management & $1.48 / 0.50$ & $1.98 / 0.69$ & $1.53 / 0.29$ & $1.77 / 0.52$ & $1.82 / 0.66$ \\
\hline Fiscal Management & $1.34 / 0.46$ & $2.17 / 0.84$ & $1.59 / 0.29$ & $1.77 / 0.53$ & $1.74 / 0.66$ \\
\hline Personal Development & $1.67 / 0.51$ & $2.37 / 0.71$ & $1.81 / 0.29$ & $2.05 / 0.63$ & $2.11 / 0.60$ \\
\hline $\begin{array}{l}\text { Research/Evaluation / } \\
\text { Assessment }\end{array}$ & $1.70 / 0.58$ & $2.23 / 0.77$ & $1.81 / 0.24$ & $2.03 / 0.64$ & $2.08 / 0.61$ \\
\hline Legal & $1.36 / 0.43$ & $1.64 / 0.48$ & $1.38 / 0.31$ & $1.67 / 0.57$ & $1.81 / 0.56$ \\
\hline Technology & $1.45 / 0.51$ & $1.70 / 0.45$ & $1.78 / 0.34$ & $1.75 / 0.40$ & $1.82 / 0.57$ \\
\hline Diversity & $1.33 / 0.57$ & $1.77 / 0.53$ & $1.29 / 0.25$ & $1.67 / 0.55$ & $1.63 / 0.66$ \\
\hline
\end{tabular}


Table 6 indicates the means and standard deviations for leadership, student contact, communication, HR management, fiscal management, personal development, research/ evaluation/assessment, legal, technology, and diversity, by institution type. Data were combined for years 2011 and 2013.

Table 6.

Measures of Central Tendency by Institution Type

\begin{tabular}{lccccc}
\hline \multirow{2}{*}{} & $\begin{array}{c}\text { Public } \\
\text { University }\end{array}$ & $\begin{array}{c}\text { Public } \\
\text { College }\end{array}$ & $\begin{array}{c}\text { Private } \\
\text { University }\end{array}$ & $\begin{array}{c}\text { Private } \\
\text { College }\end{array}$ & \begin{tabular}{c} 
Other \\
\cline { 2 - 6 }
\end{tabular} \\
\cline { 2 - 6 } M/SD & M/SD & M/SD & M/SD & M/SD \\
\hline Leadership & $1.46 / 0.65$ & $1.46 / 0.57$ & $1.00 /$. & $1.49 / 0.35$ & $1.28 / 0.25$ \\
Student Contact & $1.57 / 0.61$ & $1.81 / 0.63$ & $1.00 /$. & $1.75 / 0.40$ & $1.57 / 0.76$ \\
Communication & $1.60 / 0.57$ & $1.53 / 0.50$ & $1.00 /$. & $1.71 / 0.35$ & $1.20 / 0.20$ \\
HR Management & $1.50 / 0.71$ & $1.83 / 0.58$ & $1.00 /$. & $1.71 / 0.46$ & $1.33 / 0.35$ \\
Fiscal Management & $1.64 / 0.71$ & $1.77 / 0.63$ & $1.00 /$. & $1.79 / 0.46$ & $1.38 / 0.54$ \\
Personal Development & $1.75 / 0.82$ & $2.10 / 0.60$ & $1.17 /$. & $2.04 / 0.50$ & $1.61 / 0.25$ \\
Research/Evaluation / & $1.94 / 0.80$ & $2.07 / 0.57$ & $1.00 /$. & $2.08 / 0.50$ & $1.38 / 0.38$ \\
$\quad$ Assessment & & & & & \\
Legal & $1.50 / 0.71$ & $1.65 / 0.52$ & $1.00 /$. & $1.69 / 0.47$ & $1.47 / 0.64$ \\
Technology & $1.50 / 0.71$ & $1.77 / 0.47$ & $1.00 /$. & $1.86 / 0.36$ & $1.50 / 0.50$ \\
Diversity & $1.67 / 0.94$ & $1.59 / 0.56$ & $1.00 /$. & $1.61 / 0.55$ & $1.22 / 0.38$ \\
\hline
\end{tabular}

The researchers tested the hypothesis that attitudes toward technology and diversity would not change from 2011 (technology mean rank $=24.68$; diversity mean rank = 25.41 ) and 2013 (technology mean rank = 27.09; diversity mean rank = 25.68). Due to the unequal sample sizes and concerns over the normality of the distribution, non-parametric Mann-Whitney U tests were used (Field, 2009). The researchers also used Monte Carlo exact significance levels for greater statistical precision. The Mann-Whitney U test is functionally a non-parametric version of the Student's $t$-test, except it is able to handle violations of normality within the data. Results indicated: $\mathrm{U}=253.50, p=.582, \mathrm{Z}=-.571$, $r=.081$ for technology; and $\mathrm{U}=277.50, p=.950, \mathrm{Z}=.062, r=.001$ for diversity. These results would suggest that there were no significant differences between 2011 and 2013 in how technology and diversity were rated. It should be noted that the Mann-Whitney $\mathrm{U}$ test in this case has adequate statistical power to detect large changes (e.g., $d=.80$ ) between 2011 and 2013. However, if the change between the years were smaller (e.g., $d=.30$ ) they would not be detectable. The researchers conclude that there is tentative support for Hypothesis 1 (that attitudes towards technology and diversity were the same between 2011 and 2013). However, they offer the caveat that if there were a difference between 2011 and 2013, it would be reasonably modest.

The second hypothesis was that "economic concerns" at an institutional level would be the most frequently mentioned for 2013. A non-parametric $\chi^{2}$ goodness-of-fit test was conducted on the qualitative data coded by the researcher. Results indicated that $\chi^{2}(9)=$ $12.00, p=.213$. In other words, while economic concerns at an institutional level were the 
most commonly cited for 2013, they were not mentioned statistically more than other concerns. The researchers failed to reject the null hypothesis that economic concerns would be perceived as "more important" on an institutional level; that is, they concluded that economic concerns were not mentioned more frequently than other types of concerns.

The third hypothesis was that attitudes toward research, evaluation, and assessment (REA) would be significantly less positive than attitudes toward leadership and communication. The researchers did not think that this trend would be localized to either 2011 or 2013, and wished to pool the responses from the two years to increase the power of the analysis. However, the researchers first had to establish that the scores from 2011 and 2013 did not differ. A series of Mann-Whitney U tests were conducted and indicated that REA scores $(\mathrm{U}=337.50, p=.378, \mathrm{Z}=-.883)$, leadership scores $(\mathrm{U}=198.00, p=.087, \mathrm{Z}=$ $-1.739)$, and communication scores $(\mathrm{U}=265.50, p=.755, \mathrm{Z}=-.316)$ did not differ based on year. Because no statistically significant differences emerged between the two years for any of the three outcome variables, the researchers proceeded with pooling participant responses from 2011 and 2013. This resulted in three pooled variables: the average importance ratings of REA, leadership, and communication for 2011/2013.

The researchers compared the ratings of "importance" using the following grouping variable: REA (Group 1), leadership (Group 2), and communication (Group 3). To make these comparisons, they used the Kruskal-Wallis test, which is functionally a nonparametric version of an ANOVA. They expected the average pooled REA scores to be significantly greater (and therefore less important) than both the average pooled leadership scores and the average pooled communication scores. Results indicated that $\mathrm{H}(2)=$ $28.31, p<.001$, which would suggest that at least one of the groups significantly differed from one of the other groups. The researchers then investigated where these differences lay, using Dunn's test, which is a post-hoc test appropriate to assess group differences in Kruskal-Wallis tests. It should be noted that Dunn's test uses an adjusted significance value in the assessment of group differences (i.e., it uses a Bonferroni-type correction). While there were no significant differences between leadership and communication $\left(t^{\prime}=\right.$ $-13.55, p=.351)$, REA was significantly higher than both leadership $\left(t^{\prime}=44.80, p<.001\right)$ and communication $\left(t^{\prime}=31.25, p=.001\right)$. These results would suggest that the importance placed on REA is significantly less than the importance placed on leadership and communication. These results were consistent with the researchers' hypothesis.

The fourth hypothesis was that student affairs' degrees would be more highly valued by CSAOs in 2013 than they were in 2011. The researchers sought to determine whether the 2013 sample $(M=1.24, S D=.56)$ favoured degree programs more than their 2011 counterparts $(\mathrm{M}=1.38, \mathrm{SD}=.74)$. Unfortunately, a disproportionate number of respondents indicated that this type of professional development was "not available." Approximately $50 \%$ of respondents in 2011 indicated that they could not attest to the effectiveness of a student affairs degree; this number actually increased slightly in 2013, with 55\% of respondents indicating likewise. The researchers decided not to conduct analysis, as there was a substantial loss in power, given the number of respondents who did not respond. Additionally, the researchers were wary of conducting an analysis that might not adequately or accurately represent the views of the CSAO population.

The fifth hypothesis was that physical and mental well-being issues would be the most prevalent student issue over the subsequent five years (i.e., the researchers used only the 
2013 data). They examined the frequency data $\chi^{2}(9)=29.14, p<.001$, which suggested that the data were not evenly spread over the possible categories of concern. Further examination revealed that mental/health issues were mentioned $\sim 3.5$ times more often than expected. These results supported the researchers' hypothesis regarding the growing prioritization of physical and mental well-being issues.

In summary, the researchers found the following regarding their five hypotheses about the CSAO field in general, or about specific differences between the 2011 and 2013 samples:

1. Attitudes regarding the importance of technology and diversity would not change between 2011 and 2013. This hypothesis was tentatively supported by the data.

2. Economic concerns at an institutional level would be the most common concern. This hypothesis was not supported by the data.

3. Attitudes toward research, evaluation, and assessment would be significantly less positive than attitudes toward leadership and communication. This hypothesis was supported, as REA was rated as less important than both leadership and communication.

4. Student affairs degrees would be more valued in 2013 than in 2011. This hypothesis could not be tested, as many of the CSAOs did not have experience with student affairs degrees.

5. Physical and mental well-being issues (i.e., "health") would be identified as the most prevalent student issue for the coming five years. This hypothesis was supported by the data analysis.

\section{Discussion}

Historically, much of the academic literature addressing CSAOs consists of descriptions of problems faced at a specific institution, and how those problems were addressed (e.g., Kuh, 2013). While this type of literature is extremely important for knowledge mobilization, it is limited by being reactive. Typically, literature addressing SAPs will note a specific issue that arose on a campus and was dealt with in a specified manner. The current study approaches this paradigm differently by promoting the idea that some issues may not have to happen in order to be addressed. In other words, the researchers from the current study have introduced the possibility of being proactive with issues that CSAOs face. By polling CSAOs about their expectations of the future, the current study hopes to enable some postsecondary institutions to address issues before they become (potentially) serious. The researchers do not believe that simply having knowledge of trends will eliminate all issues; however, CSAOs may be more vigilant about detecting specific issues if they are made aware of them in advance.

The current study allowed insight into the evolution of CSAOs' perspectives. Using the same measure for both 2011 and 2013 enabled direct comparisons of perspectives. Although the sample size for 2013 was smaller than desirable, at only $18 \%$ of the CSAO population, this does not invalidate the current study, which still provides valuable information regarding the baseline of CSAOs' attitudes. Knowledge of these attitudes will be further developed with future research. Whether 2013 is a representative sample will be more evident when it is compared to other samples from other years. Because of concerns over sample representativeness, the researchers' conclusions were couched with an appropriate degree of caution. 
The results within the study have indicated that attitudes towards technology and diversity did not appear to have changed since 2011. These findings were consistent with previous literature, which has suggested that, instead, racial attitudes have become increasingly relevant to the SAP field (Wong \& Buckner, 2008). Additionally, campuses remain reliant on technology, a trend that will almost certainly continue. While the current study would not have been able to detect subtle changes, the researchers are confident that if there were attitudinal changes between 2011 and 2013, they were minimal. This would suggest a degree of stability in the CSAO field.

The economic crisis of 2008, although it has somewhat abated within Canada, is still a political and institutional reality. The researchers were surprised by the lack of significant findings indicating that CSAOs' biggest concern in 2013 was economic. Although economic concerns were the largest outcome for the frequency data collected, the differences were not statistically significant. The researchers were unsure whether this reflected inadequate power within the data to detect such patterns, or whether perhaps economic issues are perennial and respondents therefore assumed such issues would always play a role. Alternatively, the failure of economic concerns to be the "most important" concern of 2013 may reflect a broader set of concerns than imagined. In either event, the hypothesis regarding the primacy of economic concerns was not supported by the data.

The findings related to what importance CSAOs place on REA are somewhat disheartening. While attitudes toward REA were not necessarily negative, the disparity in how important REA was, as opposed to leadership or communication, demonstrates that CSAOs subordinate REA to more traditional CSAO roles. These results fit with the researchers' observation that SAPs are largely concerned with building their field professionally, rather than academically. To be fair, CSAOs are under no obligation to design and implement studies. However, developing an academically rigorous field of research may help CSAOs build and professionalize the field. Having access to appropriately gathered information may provide researchers with an opportunity to expand and refine their professional field. However, whether student affairs offices have the necessary resources and experience to perform academic research is debatable. The diminished importance of REA means that making changes to the status quo within the student affairs field is difficult and/or may be undervalued.

The researchers were surprised at the low availability of student affairs degrees. Approximately 50\% of both the 2011 and 2013 samples indicated that this type of professional development was unavailable. Given the importance of student affairs, the researchers had assumed that professional degrees in this area would receive high ratings in both years. Instead, the data suggest that CSAOs are often unfamiliar with the utility of these degrees. The broader interpretation of this finding is challenging, as it is unclear why CSAOs are unfamiliar with this professional development method. It may be that CSAOs are only speaking from experience and often have degrees not specifically related to student affairs. This explanation is plausible, as education degrees are often popular amongst CSAOs.

Unfortunately, while education degrees are undoubtedly useful amongst CSAOs, they provide a different skill set than a degree in student affairs would. Waple (2006) indicated a growing consensus that academic preparation in student affairs is necessary for an administrator to be successful in the SAP field, and that the effectiveness of education 
degrees is unclear. Interestingly, the present researchers found that approximately 70\% of CSAOs who rated student affairs degrees indicated that they were "highly effective." So, while student affairs degrees were not poorly rated, there seems to be a lack of exposure to these degrees. Whether this is because these degrees are not being offered or there is a lack of interest in them is unclear. The lack of awareness of specialized training for SAPs is consistent with Rybalkina's (2004) findings that formal academic qualifications in the area of student affairs have not been a requirement for many CSAO appointments. Although these findings are over a decade old, it appears that this issue has not been substantially ameliorated.

When asked to identify the most pressing student-related problem for the next year and the next five years, CSAOs overwhelmingly indicated that physical and mental health were major issues that needed to be confronted. What makes this particularly impressive is that health concerns did not appear on the list CSAOs generated in 2011 for a five-year outlook. In other words, in 2011, health was not identified as a long-term problem. Curiously, health was identified as being a short-term concern in 2011 (i.e., relevant to the following year), so it would appear that CSAOs may have perceived health as a transient concern, or that health was subordinated to other concerns. While CSAOs expressing concern over health is not a positive thing, it does indicate that CSAOs are cognizant of the growing concern regarding mental health-related issues. The present researchers are curious as to where this concern will be ranked in 2015, when they attempt the research again.

The similarities and attitudinal consistencies between the 2011 and 2013 data speak volumes to the collective consciousness of the CSAO field. Professionals from different institutions in different provinces often reported similar concerns for the future. This pattern indicates that professional issues are not limited to a single institution or region, which tacitly supports the idea that campuses can learn from each other. Information discovered through proactive research offers an avenue for data sharing. In general, there need to be more attempts amongst SAPs to conduct research to share with their colleagues. The good news within the current study is that research into the CSAO field has a historically unique opportunity to expand. The education level of CSAOs has been changing in recent years, with an increasing number of respondents having graduate degrees. In 2005, 85\% of respondents indicated a graduate school level of education (Browne, 2007), compared to $97 \%$ in 2011 and $100 \%$ in 2013. Although these numbers are approximations of the "real" percentages, they indicate that CSAOs are increasingly gaining levels of education that promote the understanding of research. If developments within the CSAO field are to be made, now is the ideal time.

\section{Limitations}

The most substantial limitation of the current study is the lower response rate in 2013 (18.8\%) compared to the response rate in 2011 (28.5\%). Because of the difference in sample size, the characteristics of the sample population may have been non-representative of the whole CSAO population. Unfortunately, the researchers were unable to determine why the response rate was lower in 2011 than in 2013. The small sample of CSAOs meant that any potential participant's refusal to participate lowered the overall response rate by approximately 1\% (because the total number of CSAOs was approximately 100). While it is theoretically possible to survey respondents about their refusal to participate, this was impractical 
for two reasons: (i) because the survey was anonymous, there was no way to distinguish participants from non-participants, meaning that all CSAOs (regardless of whether they had participated) would have received an email asking them to explain why they had not; (ii) because of positional changes within postsecondary institutions, a different population of CSAOs would be surveyed, which would limit the meaningfulness of the data.

Although this study did reveal important information regarding the attitudes of CSAOs as well as trends in these attitudes, some limitations must be acknowledged. Because the list of CSAOs in Canada was not exhaustive, there is the possibility of unintentional sampling bias. It is not clear how this issue would be resolved, as there is no definitive list of persons involved in student affairs; this is why the researchers relied on a professional membership list as a starting point for the institutions where CSAOs would be employed. Additionally, the difference in sample sizes between the two years reduced the power for finding effects. However, this would have led to the researchers missing findings rather than reporting findings that were not really there. As noted earlier, having a population of $\sim 100$ respondents means that a sample size of $18 \%$ may produce issues with representativeness. Future iterations of this research will reveal whether the 2013 data was anomalous or consistent with other years. Finally, the information may contain a provincial bias. The researchers did not receive any data from French-speaking institutions; whether this reflects an underlying response bias is unclear.

Unfortunately, the researchers did not provide space for general comments in either iteration of the survey. To address these potential issues, the next iteration of the survey (to be held in 2015) will include a "Decline to participate" option. Persons who select this option will be prompted to provide a reason for their non-participation. Hopefully, the researchers will thereby be able to understand non-participation rates and effectively adapt their research strategy. While the researchers did provide a contact email address for persons in 2011 and 2013, no respondent feedback was received. In the next iteration, they will also provide space for "general feedback," where respondents can provide information that may not have been covered by the survey.

A potential drawback of the current study is the use of the Rybalkina (2004) measure to assess trends amongst CSAOs. This measure of behaviours and attitudes amongst SAPs is a decade old and may not be the ideal method for assessing the ever-evolving field of student affairs. While the Rybalkina measure touches upon core constructs of great relevance (e.g., leadership, communication), it should be updated to reflect the greater range of responsibilities and duties that CSAOs now have. However, designing an appropriate measure of trends and tendencies requires academic research. This presents a "Catch-22" situation in which research on CSAOs is needed, but in order for the research to be conducted, more research has to be done. This places researchers in a position where they may initially need to use an inadequate assessment tool to gather data on CSAOs (i.e., the Rybalkina measure), in order to gain feedback on the construction of a better tool. Ideally, CSAO research should initially focus on how to improve existing measures so that a representative and adequate assessment of this professional group is possible. In the future, these researchers will retain core elements of the Rybalkina measure (so longitudinal comparisons can be made) but will have modules that are more focused on investigating the duties and responsibilities of CSAOs. 
The goals of the current study, although realized to a large extent, were challenging because of what a CSAO may be responsible for. Many of the CSAOs indicated a variety of titles, responsibilities, and overall priorities. While there was often overlap in the duties CSAOs were expected to perform, this overlap was not perfect. At first glance, this would appear to limit the utility of the current study, but the authors suggest that this not the case. CSAOs, when presented with the information from the current study, will be able to make decisions as to whether they believe specific trends or concepts are relevant to their own institutions. Moreover, the similarities between CSAOs are such that trends were often shared between institutions. So, while there are differences between titles, responsibilities, and overall priorities, this does not indicate the absence of similarities.

The variability within the CSAO group touches upon an important issue: the SAP field would benefit from standardization to clarify what CSAOs are responsible for, or what their duties include. A more concise conceptualization of CSAOs would result in a better measure of their responsibilities. The current study was somewhat limited because aspects that could be related to CSAOs were omitted due to constraints of time and space. Additionally, a better understanding of what CSAOs do would allow professionals in differently named positions to understand how they are professionally linked.

\section{Future Directions}

The researchers hope that CSAOs in this journal's readership will see the current study as an impetus to become more heavily involved with the research, evaluation, and assessment of the SAP field. Student affairs not only is a professional vocation but also provides a rich opportunity for interested SAPs to conduct research. While some professionals have investigated the SAP field, there are many avenues for future research. Academic investigation should be perceived as necessary for advancement, not superfluous.

More distantly, the present researchers hope that persons interested in student affairs will seek out professional accreditation in that field. As noted earlier, while education degrees appear to be the norm, a professional degree in student affairs may provide certain advantages to CSAOs. From a planning perspective, the researchers hope that professional associations in Canada will take an interest in sharing and discussing future trends within the student affairs field. As mentioned above, the authors of the current study intend to gather further longitudinal data in 2015 with a modified Rybalkina (2004) measure. Some of the reasons for engaging in this ongoing assessment include: tracking the changing demographics of CSAOs, and assessing the emerging trend and issues that affect students, student-services staff, and the institution. Overall, the researchers are optimistic that interest in proactive CSAO research will become a norm rather than a novelty.

\section{Acknowledgement}

The authors would like to acknowledge the assistance provided by Sandy Brennan, who was our contact with Student Voice at Memorial University of Newfoundland. 


\section{References}

Browne, J. (2007). Mentoring: The number one professional development method. Communiqué, 1(8), 17-18.

Browne, J., \& Shea, R. (2002). The Canadian chief student affairs officer: Demographics, trends, challenges and needs. Communiqué, 2(3), 20-21.

Carini, R., Kuh, G., \& Klein, S. (2006). Student engagement and student learning: Testing the linkages. Research in Higher Education, 47, 1-32.

Duenwald, M. (2004, October 26). The dorms may be great, but how's the counseling? The New York Times. Retrieved from http://www.nytimes.com/2004/10/26/health/ psychology/26cons.html

Ellis, S. E. (2010). But does it really work? A vision for student services, 2002-2007. New Directions for Student Services, 132, 87-100. doi:10.1002/ss.378

Field, A. (2009). Discovering statistics using SPSS: (and sex and drugs and rock ' $n$ ' roll) (3rd ed.). Los Angeles, CA: Sage.

Hardy-Cox, D., \& Strange, C. C. (2010). Foundations of student services in Canadian higher education. In D. Hardy-Cox \& C. C. Strange (Eds.), Achieving student success: Effective student services in Canadian higher education (pp. 5-17). Montreal, QC: McGill-Queen's University Press.

Jou, Y. H., \& Fukada, H. (2002). Stress, health, and reciprocity and sufficiency of social support: The case of university students in Japan. Journal of Social Psychology, 142, 353-370.

Kuh, G., Kinzie, J., Schuh, J., \& Whitt, E. (2011). Fostering student success in hard times. Change, 43, 12-19.

Kuh, G. D. (2013). Promise in action: Examples of institutional success. New Directions for Higher Education, 161, 81-90. doi:10.1002/he.20048

Lawrence, J. F. (2007). Connecting academic and student services. New Direction for Higher Education, 139, 77-86. doi:10.1002/he.269

Leonard, H. S., \& Marquardt, M. J. (2010). The evidence for the effectiveness of action learning. Action Learning: Research and Practice, 7, 121-136.

McGraw, C. E. (2011). Reflections on building capacity as a supervisor in college student services. New Directions for Student Services, 136, 17-25. doi:10.1002/ss.410

Pittman, J. (2012). Student services and auxiliary enterprises. New Directions for Student Services, 137, 29-39. doi:10.1002/ss.20012

Pledge, D., Lapan, R., Heppner, P., Kivlighan, D., \& Roehlke, H. (1998). Stability and severity of presenting problems at a university counseling center: A 6-year analysis. Professional Psychology: Research and Practice, 29, 386-389.

Russel, J. (2010). Counseling services. In D. Hardy-Cox \& C. C. Strange (Eds.), Achieving student success: Effective student services in Canadian higher education (pp. 113-123). Montreal, QC: McGill-Queen's University Press. 
Rybalkina, O. (2004). A comparative analysis of student affairs administrators' competencies and professional development opportunities in the United Sates and the United Kingdom (Unpublished doctoral dissertation). University of Toledo, Ohio.

Sandeen, A., \& Barr, M. J. (2006). Critical issues for student affairs: Challenges and opportunities. New York, NY: Jossey-Bass.

Shuler, P. A. (2000). Evaluating student services provided by school-based health centers: Applying the Shuler Nurse Practitioner Practice Model. Journal of School Health, $70,348-352$.

Walker, J. L. (1994a). National perception data-benchmarking student life. Report prepared for the Canadian University Survey Consortium. Winnipeg, MB: Walker Associates.

Walker, J. L. (1994b). Undergraduate experience at eight Canadian universities. Report prepared for the Canadian University Survey Consortium. Winnipeg, MB: Walker Associates.

Walker, J. L. (1996). Survey of undergraduate experience at 10 Canadian universities. Report prepared for the Canadian University Survey Consortium. Winnipeg, MB: Walker Associates.

Walker, J. L. (1997). A graduating student survey at nine Canadian universities. Report prepared for the Canadian University Survey Consortium. Winnipeg, MB: Walker Associates.

Walker, J. L. (1998). Survey of first-year university students at nineteen Canadian universities. Report prepared for the Canadian University Survey Consortium. Winnipeg, MB: Walker Associates.

Walker, L., Stewart, D., \& Eerkes, D. (2009). Establishing institutional responses to safety threats. Communiqué, 9(3), 25-26.

Waple, J. N. (2006). An assessment of skills and competencies necessary for entrylevel student affairs work. NASPA Journal, 43(1), 1-18.

Wong, M. P. A., \& Buckner, J. (2008). Multiracial student services come of age: The state of multiracial student services in higher education in the United States. New Directions for Student Services, 123, 43-51. doi:10.1002/ss.285

\section{Contact Information}

Jennifer Browne

Career Development \& Experiential Learning

Memorial University of Newfoundland

jbrowne@mun.ca

Jennifer Browne is the Director of Career Development \& Experiential Learning at Memorial University. She is an active member of the student-affairs and career-development communities in Canada. Her research interests include experiential learning and student affairs and services. 
David Speed is a doctoral candidate in experimental psychology at Memorial University. His research interests include the role of religious identity in the promotion of health. In his spare time he enjoys reading, squash, and watching "so-bad-they're-funny" movies with his partner, Betsy.

Lilly J. Schubert Walker, former Dean of Student Affairs and Services at Memorial University, taught both undergraduate and graduate students in psychology until her retirement in 2013. 